\title{
PERBANDINGAN EFEKTIFITAS TEKNIK RELAKSASI DAN GENGGAMAN JARI TERHADAP PENURUNAN NYERI PADA PASIEN POST OPERASI SECTIO CAESARE DI RUMAH SAKIT UNDATA PROVINSI SULAWESI TENGAH
}

\author{
Effectivennes Ratio of Relaxation Technique and Finger Grasping Toward Reducing of \\ Pain For Post Op Sectio Caesarea Patient In Undata Hospital Central Sulawesi Province
}

\author{
Misnawati \\ STIKes Widya Nusantara Palu \\ misnawatilamidji@gmail.com / Hp:085200004078
}

\begin{abstract}
ABSTRAK
Teknik relaksasi dan genggaman jari merupakan suatu bentuk terapi relaksasi untuk menyeimbangkan energi tubuh yang dapat membantu pasien dalam menggontrol diri ketika timbulnya perasaan kurang menyenangkan yang dapat menimbulkan nyeri, stres fisik serta emosi. Penelitian dalam hal ini bertujuan mengidentifikasi perbandingan efektifitas teknik relaksasi dan genggaman jari terhadap penurunan nyeri pada pasien post operasi sectio caesarea di ruangan Matahari Rumah Sakit Umum Daerah Undata Provinsi Sulawesi Tengah. Dalam Penelitian ini digunakan desain quasy exsperiment (pre and post test without control) dengan metode kuantitatif. Penelitian ini dilakukan tanggal 25 Juli sampai dengan 27 Agustus 2018. Semua pasien post operasi sectio caesarea merupakan Populasi dalam penelitian ini selama penelitian berlangsung. Jumlah sampel dihitung dengan menggunakan rumus rerata uji hipotesis two tail dengan nilai $\sigma 2=5,36, \mu \mathrm{o}=5,07, \mu \mathrm{a}=1,80, \alpha=1,96$ dan $\beta=0,84$ sehingga jumlah sampel adalah 8 responden dipilih dengan teknik quota sampling. Data dihitung dengan menggunakan uji Wilcoxon dengan didapatkan nilai $p=0,011(\alpha \leq=0,05)$ pada tingkat kemaknaan $\alpha=0,05$ atau 95\%). Pada hasil penelitian pretest didapatkan lebih banyak responden mengatakan nyeri berat terkontrol dan posttest didapatkan lebih sedikit responden mengatakan nyeri ringan. Kesimpulan dari penelitian ini yaitu terdapat perbandingan efektifitas teknik relaksasi dan genggaman jari terhadap penurunan nyeri pada pasien post operasi sectio caesarea di ruangan Matahari Rumah Sakit Umum Daerah Undata Provinsi Sulawesi Tengah. Oleh karena itu, peneliti menyarankan agar perawat dapat menerapkan teknik relaksasi dan genggam jari selama 20 menit sebagai salah satu manajemen nyeri.
\end{abstract}

Kata Kunci: Relaksasi,Genggaman Jari, dan Nyeri

\begin{abstract}
Relaxation technique and finger grasping is one of relaxation therapy that could help patient in self controlling when feeling pain or uncomfortable, physical stress and pain irritable. The aim of this research to identify the effectivennes ratio of relaxation technique and finger grasping toward reducing of pain for post op section caesarea patient in Matahari Ward of Undata Hospital, Central Sulawesi Province. This is quantitative research with quasy experiment (pre and post test without control). This research done from July 25 until August 27, 2018. All patient underwent section caesarea operation in Matahari Ward of Undata Hospital are population of this research was. Sample was calculated using by average two tail formula with $\sigma 2=5,36, \mu o=5,07, \mu a=1,80, \alpha=1,96$ and $\beta=$ 0,84 that the sample is 8 respondent taken by quota sampling technique. Data was calculated using Wilcoxon test with $\alpha$-value $=0,05$ or $95 \%$ get $p$-value $=0,011(\alpha \leq 0,05)$. Result found of pretest that have most respondent is suffered heavy pain controlled and posttest that have most respondent is suffered mild pain. Conclusion, that have Effectivennes Ratio relaxation technique and finger grasping toward reducing of pain for post op section caesarea patient in Matahari Ward of Undata Hospital, Central Sulawesi Province. Suggest, nurse could implement the relaxation technique and finger grasping during 20 minute as a pain management.
\end{abstract}

Keywords: Relaxation,Finger Grasping, Pain 


\section{PENDAHULUAN}

Tindakan pembedahan sectio caesarea perlu dilakukan karena janin tidak dapat dilahirkan secara normal atas indikasi yang berasal dari ibu maupun janin, sehingga terjadi kerusakan jaringan akibat luka insisi pada dinding abdomen dan dinding uterus. Tindakan tersebut menjadikan nyeri sebagai salah satu faktor keluhan pasien post operasi ${ }^{(1)}$.

Intervensi dalam menangani nyeri dilakukan dengan manajemen nyeri secara farmakologi maupun bukan farmakologi. Manajemen dalam farmakologi dilakukan dengan pemberian anti nyeri untuk mengurangi rasa nyeri ${ }^{(2)}$. Manajemen bukan farmakologi dapat dilakukan dengan berbagai tindakan mencakup keadaan perilaku dan Potensi. meliputi tindakan menenangkan diri, mengurngi rasa tidak nyaman, melakukan relaksasi, mengontrol hayalan, serta umpan balik dari diri, hypnosis,stimulus kutaneus, accupresure, musik dan sentuhan terapeutik ${ }^{(3)}$.

Manajemen nyeri non farmakologi dengan teknik relaksasi dan genggam jari yaitu terapi yang menggunakan sentuhan tanga dan tehnik pernafasan untuk mengimbangi energi tubuh yang dapat membantu pasien dalam menggontrol diri ketika timbulnya perasaan yang kurng menyenangkan yang dapat menimbulkan nyeri, stres fisik serta emosi ${ }^{(4)}$.

World Health Organization (WHO) tahun 1989 menentukan standar rata-rata tindakan Operasi pembedahan sectio caesarea di suatu negara dalam kisaran $10-15 \%$ per 1.000 kelahiran di Dunia. Sedangkan di Indonesia Operasi pembedahan sectio caesarea harus berdasarkan indikasi medis tertentu dalam setiap kehamilan yang disertai komplikasi ${ }^{(5)}$.

Survei pengambilan data awal di Ruangan Matahari RSUD Undata dengan wawancara kepada Kepala Ruangan, bahwa terdapat standar prosedur operasional (SPO) tentang teknik relaksasi pada pernafasan sedangkanbelum terdapat standar prosedur operasional (SPO) tentang teknik genggam jari. SPO tersebut diperlukan sebagai panduan untuk melakukan manajemen nyeri non farmakologi dengan melakukan teknik relaksasi dan genggam jari pada pasien yang selesai dilakukan operasi. Hasil tindakan awal perlakuan dalam perbadingan efektifitas teknik relaksasi dan genggam jari pada 3 pasien post operasi sectio caesarea 6 sampai 8 jam post operasi di Ruangan Matahari RSUD Undata menunjukan bahwa terdapat penurunan skala nyeri setelah dilakukan teknik relaksasi dan genggam jari dengan hasil ukur pretest yaitu nyeri berat terkontrol sedangkan posttest yaitu nyeri ringan dan nyeri sedang. Berdasarkan uraian diatas belum terdapat informasi penelitian maupun publikasi secara ilmiah tentang teknik genggam jari yang dilakukan di Provinsi Sulawesi Tengah khusunya di RSUD Undata sehingga peneliti perlu untuk melakukan penelitian dengan judul perbandingan efektifitas teknik relaksasi dan genggam jari terhadap penurunan nyeri pada pasien post operasi sectio caesarea di Ruangan Matahari Rumah Sakit Umum Daerah Undata Provinsi Sulawesi Tengah. Tujuan penelitian yaitu untuk mengidentifikasi perbandingan efektifitas teknik relaksasi dan genggam jari terhadap penurunan nyeri pada pasien post 
operasi sectio caesarea di ruangan Matahari Rumah Sakit Umum Daerah Undata Provinsi Sulawesi Tengah.

\section{METODE PENELITIAN}

Jenis penelitian ini digunakan desain quasy exsperiment (pre and post test without control) dengan metode kuantitatif. Penelitian dilakukan di Ruangan Matahari RSUD Undata Provinsi Sulawesi Tengah pada tanggal 25 Juli sampai 27 Agustus 2018. Populasi penelitian adalah semua pasien post operasi sectio caesarea selama penelitian berlangsung. Jumlah sampel dihitung dengan menggunakan rumus rerata uji hipotesis pada rata-rata kelompok independen (two tail) dengan nilai $\sigma 2=5,36, \mu \mathrm{o}=5,07, \mu \mathrm{a}=1,80$, $\alpha=1,96$ dan $\beta=0,84$ sehingga jumlah sampel adalah 8 responden, sampel dipilih dengan menggunakan teknik quota sampling. Sampel dipilih berdasarkan kriteria ketercukupan yaitu pasien setelah operasi sectio caesarea 6 sampai dengan 8 jam, dan kriteria ekslusi yaitu pasien setelah operasi sectio caesarea kurang dari 6 jam dan lebih dari 8 jam post operasi.

\section{HASIL}

Tabel 1. Distribusi Frekuensi Karakteristik subjek setelah operasi sectio caesarea di Ruangan Matahari RSUD Undata Provinsi Sulawesi Tengah

\begin{tabular}{ccc}
\hline Karakteristik & f & \% \\
\hline Umur (Tahun) & & \\
$17-25$ & 1 & 12.5 \\
$26-35$ & 6 & 75.0 \\
$36-45$ & 1 & 12.5 \\
\hline Pekerjaan & & \\
URT & 6 & 75.0 \\
Honor & 2 & 25.0 \\
\hline
\end{tabular}

Sumber : Data Primer 2018

Tabel 1 menunjukan pada kelompok intervensi dari 8 subjek, sebagian besar memiliki umur 26-35 tahun berjumlah 6 orang $(75,0 \%)$ dan memiliki pekerjaan urusan rumah tangga (URT) berjumlah 6 orang $(75 \%)$.

Tabel 2. Distribusi Frekuensi skala nyeri Subjek sebelum perlakuan (pretest) teknik relaksasi dan genggaman jari di Ruangan Matahari RSUD Undata Provinsi Sulawesi Tengah

\begin{tabular}{lcc}
\hline Skala Nyeri & f & \% \\
\hline $1-3$ & 0 & 0 \\
$4-6$ & 1 & 12.5 \\
$7-9$ & 6 & 75.0 \\
10 & 1 & 12.5 \\
\hline Total & 8 & $100 \%$ \\
\hline
\end{tabular}

Sumber : Data Primer 2018

Tabel 2 menunjukan pada kelompok intervensi skala nyeri pada subjek sebelum perlakuan (pretest) teknik relaksasi dan genggaman jari terdapat 6 orang $(75,0 \%)$ memiliki nyeri berat terkontrol.

Tabel 3. Distribusi skala nyeri responden sesudah perlakuan (posttest) teknik relaksasi dan genggam jari di Ruangan Matahari RSUD Undata Provinsi Sulawesi Tengah

\begin{tabular}{ccc}
\hline Skala Nyeri & f & \% \\
\hline $1-3$ & 6 & 75.0 \\
$4-6$ & 2 & 25.0 \\
$7-9$ & 0 & 0 \\
10 & 0 & 0 \\
\hline Total & 8 & $100 \%$ \\
\hline
\end{tabular}

Keterangan: Data Primer 2018

Tabel 3 menunjukan pada kelompok intervensi skala nyeri subjek sesudah perlakuan (posttest) pada teknik relaksasi dan genggaman jari terdapat 6 orang $(75,0 \%)$ memiliki nyeri ringan. 
Tabel 4 Perbandingan Efektifitas teknik relaksasi dan genggaman jari terhadap penurunan nyeri pada pasien setelah operasi sectio caesarea di Ruangan Matahari Rumah Sakit Umum Daerah Undata Provinsi Sulawesi Tengah

\begin{tabular}{|c|c|c|c|c|c|c|c|c|c|c|c|}
\hline \multirow{3}{*}{$\begin{array}{c}\text { Teknik Relaksasi } \\
\text { Dan Genggam } \\
\text { Jari }\end{array}$} & \multicolumn{8}{|c|}{ Skala Nyeri } & \multirow{2}{*}{\multicolumn{2}{|c|}{ Total }} & \multirow{2}{*}{ P-Value } \\
\hline & \multicolumn{2}{|c|}{ NR* } & \multicolumn{2}{|c|}{$\mathbf{N S} * *$} & \multicolumn{2}{|c|}{ NBT*** } & \multicolumn{2}{|c|}{ NBTT***** } & & & \\
\hline & $\mathbf{f}$ & $\%$ & $\mathbf{f}$ & $\%$ & f & $\%$ & $\mathbf{f}$ & $\%$ & $\mathbf{f}$ & $\%$ & \multirow{4}{*}{0,011} \\
\hline Pretest & 0 & 0 & 1 & 12.5 & 6 & 75 & 1 & 12.5 & 8 & 100 & \\
\hline Posttest & 6 & 75 & 2 & 25 & 0 & 0 & 0 & 0 & 8 & 100 & \\
\hline Jumlah & 6 & 75 & 3 & 37.5 & 6 & 75 & 1 & 12.5 & & & \\
\hline
\end{tabular}

Keterangan: Data Primer 2016

*Nyeri Ringan **Nyeri Sedang, ***Nyeri Berat Terkontrol, ****Nyeri Berat Tidak Terkontrol

Tabel 4 menunjukan bahwa sebagian besar responden sebelum perlakuan (pretest) teknik relaksasi dan genggam jari mengalami nyeri berat terkontrol berjumlah 6 orang $(75.0 \%)$ dan sesudah perlakuan (posttest) teknik relaksasi dan genggam jari mengalami nyeri ringan berjumlah 6 orang $(75.0 \%)$ Hasil uji statistik dengan menggunakan uji wilcoxon didapatkan nilai $p=0,011 \quad(\alpha \leq 0,05)$, berarti Ho ditolak artinya adanya hubungan teknik relaksasi dan genggaman jari terhadap penurunan nyeri pada pasien post operasi sectio caesarea di Ruangan Matahari Rumah Sakit Umum Daerah Undata Provinsi Sulawesi Tengah

\section{PEMBAHASAN}

A. Gambaran Nyeri Pada Pasien Pasca Operasi Sectio Caesarea Sebelum Perlakuan (Pretest) pada Teknik Relaksasi Dan Genggaman Jari

Hasil dari analisis univariat, menunjukan bahwa kelompok intervensi sebagian besar responden sebelum perlakuan (pretest) teknik relaksasi dan genggaman jari memiliki nyeri berat terkontrol. Persepsi nyeri yang dirasakan berbeda-beda pada setiap responden tergantung pada mekanisme koping masing-masing individu, adanya pemberian anestesi sesaat sebelum dilakukannya operasi dan faktor pengalaman operasi sebelumnya menyebabkan persepsi nyeri yang dirasakan pasien rata-rata adalah skala nyeri berat terkontrol. Nyeri merupakan kondisi yang mempengaruhi seseorang berupa perasaan tidak nyaman secara fisik maupun mental bersifat sangat subjektif karena perasaan nyeri pada setiap individu berbeda dalam skala atau tingkatannya, dimana nyeri timbul ketika adanya kerusakan jaringan menyebabkan individu bereaksi untuk menghilangkan rangsangan nyeri ${ }^{(6)}$.

B. Gambaran Nyeri Pada Pasien Pasca Operasi Sectio Caesarea Sesudah (Posttest) Perlakuan pada Teknik Relaksasi dan Genggaman Jari

Hasil dari analisis univariat, menunjukkan bahwa Kelompok intervensi sebagian besar responden sesudah perlakuan (posttest) pada teknik relaksasi dan genggaman jari memiliki nyeri ringan. Terjadinya penurunan nyeri sesudah dilakukan teknik relaksasi dan genggaman jari dipengaruhi oleh kemampuan setiap responden memfokuskan perhatiaanya pada nyeri yang timbul, sehingga dapat mempengaruhi perasaan nyeri yang dirasakan dan menyebabkan persepsi nyeri yang akan dirasakan pasien rata-rata adalah nyeri ringan. 
Dalam teknik relaksasi napas dapat mengurangi nyeri dengan meminimalkan aktivitas yang berlebihan. Bila sistem saraf otonom. Meningkat akan mempengaruhi aktivitas serta komponen saraf parasimpatik vegetatif secara stimulan, sehingga teknik tersebut dapat mengontrol intensitas reaksi terhadap rasa nyeri serta mengurangi sensasi nyeri yang $\operatorname{ada}^{(7)}$.

Mekanisme pada relaksasi genggaman jari dalam pengaruh penurunan nyeri menurut teori gate-control, dimana nyeri memiliki komponen emosional dan kognitif serta sensasi secara fisik. Teori gate-control mengatakan bahwa mekanisme "gerbang" disepanjang sistem saraf pusat dapat mengatur atau bahkan menghambat implusimplus nyeri pada saat "gerbang" dalam posisi terbuka dan akan dihentikan pada saat "gerbang" tertutup. Penutupan "gerbang" merupakan dasar terhadap intervensi non farmakologi dalam penanganan nyeri ${ }^{(8)}$.

Relaksasi genggaman jari dengan menggunakan sentuhan tangan yang sederhana dan tehnik pernapasan dilakukan dapat menyeimbangkan energi dalam tubuh yang kemudian melepaskan penutupan (gerbang $)^{(9)}$.

C. Efektifitas Teknik Relaksasi Dan Genggaman Jari Terhadap Penurunan Nyeri Pada Pasien Post Operasi Sectio Caesarea Di Ruangan Matahari Rumah Sakit Umum Daerah Undata Provinsi Sulawesi Tengah

Hasil dari analisis bivariat, menunjukkan bahwa terdapat sebagian besar memiliki nyeri berat tidak terkontrol sebelum perlakuan (pretest), penurunan nyeri sesudah perlakuan (posttest) sebagian besar memiliki nyeri ringan. Hasil uji statistik menunjukan terdapat Efektifitas teknik relaksasi dan genggaman jari terhadap penurunan nyeri pada pasien post operasi sectio caesarea di Ruangan Matahari Rumah Sakit Undata Daerah Undata Provinsi Sulawesi Tengah.

Terdapat perbandingan nyeri sebelum dan sesudah perlakakuan teknik relaksasi dan genggaman jari dipengaruhi oleh mekanisme koping masing-masing responden dan bagaimana responden memfokuskan perhatiaannya pada saat peneliti melakukan perlakuan teknik relaksasi dan genggam jari sehingga mempengaruhi persepsi nyeri yang dirasakan responden.

Pada teknik relaksasi napas menurut teori aktifitas retikuler dapat mengatasi nyeri,seperti ketika seseorang menerima masukan sensori yang cukup atau berlebihan, maka dapat menghambat stimulus nyeri sehingga menyebabkan terhambatnya implus nyeri ke otak (nyeri berkurang atau tidak dirasakan). Stimulus nyeri yang dirasakan oleh klien menjadi berkurang, bila Stimulus sensori yang menyenangkan akan merangsang sekresi endorfin ${ }^{(10)}$.

Perlakuan teknik relaksasi genggaman jari akan mengakibatkan stimulus nyeri terhambat dan berkurang ,sehingga menghasilkan implus yang dikirim melalui serabut saraf aferen non-nosiseptor mengakibatkan "gerbang" tertutup. 
Berdasarkan teori two gate control menyatakan bahwa dengan adanya relaksasi, maka implus nyeri akan dihambat dan mengakibatkan tertutupnya "gerbang" di thalamus kemudian stimulasi terhambat terdapat satu pintu "gerbang" lagi di thalamus yang mengatur implus nyeri dari nervus trigeminus. sehingga intensitas nyeri berkurang untuk kedua kalinya ${ }^{(5)}$. Hasil ini sama dengan penelitian terdahulu yaitu pada pasien post operasi laparatomi di RS PKU Muhammadiyah Gombong dinyatakan bahwa teknik relaksasi genggaman jari dapat menimbulkan efek terhadap penurunan intensitas nyeri ${ }^{(5)}$.

\section{KESIMPULAN DAN SARAN}

Dari penelitian ini didapatkan perbandingan efektifitas teknik relaksasi dan genggaman jari terhadap penurunan nyeri pada pasien post operasi sectio caesarea. Nyeri pada pasien sebelum dilakukan teknik relaksasi dan genggaman jari rata-rata mengalami nyeri berat terkontrol. Sedangkan Nyeri pada pasien post operasi sectio caesarea sesudah dilakukan teknik relaksasi dan genggaman jari menurun menjadi nyeri ringan. Bagi perawat dan Bidan diharapkan dapat menerapkann teknik relaksasi dan genggam jari selama 20 menit per hari sebagai salah satu manajemen untuk menurunkan nyeri.

\section{UCAPAN TERIMA KASIH}

Alhamdulillah Wasyukurillah penulis panjatkan kepada Allah SWT yang telah memberikan anugerah, kesehatan, petunjuk serta limpahan rahmat dan hidayah-Nya sehingga artikel ini dapat terbit. Penulis mengucapkan terima kasih banyak kepada Ketua STIKes Widya Nusantara Palu yang telah memberikan kesempatan dan bantuan dana sehingga penelitian ini dapat terlaksana, Ketua LPM dan LPPM yang telah banyak membantu serta memberikan masukan-masukan kepada peneliti, Kepada Direktur UPD.RSUD Undata Provinsi Sulawesi Tengah beserta jajarannya yang telah mengijinkan dan membantu peneliti dalam pelaksaan penelitian.

\section{DAFTAR PUSTAKA}

1. Jitowiyono S, Kristiyanasari W. 2012. Asuhan Keperawatan Post Operasi Pendekatan NANDA, NIC, NOC. Yogyakarta (ID): Nuha Medika.

2. Prasetyo S. 2010. Konsep dan Proses Keperawatan Nyeri. Yogyakarta (ID): Graha Ilmu.

3. Sulistyawati A. 2009. Asuhan Kebidanan pada Ibu Nifas. Yogyakarta (ID): Andi.

4. Pinandita I, Purwanti E, Utoyo B. 2012. Pengaruh Teknik Relaksasi Genggam Jari Terhadap Penurunan Intensitas Nyeri Pada Pasien Post Operasi Laparatomi. Jurnal Ilmiah Kesehatan Keperawatan, Volume 8.

5. [DEPKES RI] Departemen Kesehatan Republik Indonesia. 2001. Profil Kesehatan Indonesia 2001 Menuju Indonesia sehat 2010. Jakarta (ID): DEPKES RI.

6. Hidayat A A. 2006. Pengantar Kebutuhan Dasar Manusia: Aplikasi Konsep Dan Proses Keperawatan. Jakarta (ID): Selemba Medika.

7. Smeltzer, Bare. 2002. Buku Ajar Keperawatan Medikal Bedah, Edisi 8, Volume 3. Jakarta (ID): ECG

8. Potter P A. Perry A G. 2010. Fundamental Keperawatan Edisi 7, Buku 2. Jakarta (ID): Selemba Medika.

9. Hill R Y. 2011. Nursing From Inside-Out: Living and Nursing From The Highest Point Of Your Consciousness. London (GB): Jones and Bartlett Publishers.

10. Tamsuri A. 2007. Konsep dan Penatalaksanaan Nyeri. Jakarta (ID): EGC 